Conclusion: Although less common than BT, PT is associated with higher prehospital and ED mortality. Increased scene time and the number of procedures was associated with greater mortality for both BT and PT. Further study is required to better understand any causal relationships between prehospital times, interventions, and patient outcomes.

Prehosp Disaster Med 2017;32(Suppl. 1):s172-s173

doi:10.1017/S1049023X17004617

Emergency Care in Cases of Occupational Traumas Among Members of a Vessels Crew, on Sea Transport Ships of Northern Water's Basin

Konstantin A. Shapovalov

Chair Of Economics, Management And Law In Education, State Autonomous Agency of Education Additional Professional Education of Republic of Komi "Komi Republican Institute for Development of Education”, Syrtyvkar/Russian Federation

Study/Objective: Sea transport fleet is the main supplier of goods for commercial enterprises and settlements on the Arctic coast of Russia.

Background: Extreme conditions of navigation in the northern latitudes lead to the creation of dangerous situations for occupational traumas.

Methods: There were 1,367 damages with disability that occurred on vessels of sea transport fleet (208.1 per 1,000 employees).

Results: Heightened risk for traumas where the ship's work related to maintenance and repair mechanisms of the engine room (124.4); galley (73.4); maintenance of deck machinery (69.2); handling by the crew (54.8); moving on ladders and decks (44.9); mooring (30.2); machine tools (9.6); and with hatch covers (7.0). Blunt trauma applied in most cases (173.0), sharp (11.0), and thermal agents (11.0). Poisoning by acid, alkali, metal vapor, carbon monoxide, and poisons amounted just $2.4 \%$. Alcohol intoxication among the sailors of the transport fleet was set to $8.9 \%$ of occupational traumas on sea transport fleet (18.0). Fractures of the bones of various localization occurs 2.5 times more frequently, and severe bruising almost 2.9 times. Bone fractures are the leading type of damage in the structure, in all the anatomical and functional segments ( $\mathrm{P}<.001)$, including the closure, amounted to $85.5 \%$ of cases and open ones $-14.5 \%(\mathrm{P}<.001)$.

Conclusion: For occupational traumas on ships, $27.7 \%$ of patients (54.1) were surgical procedures designed to stop bleeding from wounds, toilet of antiseptic solutions with elements of surgical treatment, and application of aseptic and plaster casts. More than one-half of the patients $(63.6 \% ; 123.7)$ were treated conservatively, and only 9.7\% (17.7) were subjected to surgical intervention. Complications occurred in $15.5 \%$ of patients. The average number of disability days was 42.7; bed days 26.4 . Recovery occurred in $85.4 \%$ (17.5) affected seafarers; they were transferred to light work, followed by vocational rehabilitation $7.5 \%$ (15.8), set disability 1.4\% (2.8). Mortality was $5.7 \%$ (12.0).

Prehosp Disaster Med 2017;32(Suppl. 1):s173

doi:10.1017/S1049023X17004629
Perceived Collaboration during Mining Incidents - Focus Group Discussions with Mining Workers and Managers, Rescue Service Personnel, and Ambulance Personnel Sofia Karlsson ${ }^{1}$, Gunnar Engström ${ }^{2}$, Ulf Björnstig ${ }^{1}$, Britt-Inger Saveman ${ }^{3}$

1. Department Of Surgical And Perioperative Sciences, Section Of Surgery, Umeå University, Umeå/Sweden

2. Department Of Public Health And Clinical Medicine, Occupational And Environmental Medicine, Umeå University, Umeå/Sweden

3. Department Of Nursing, Umeå University, Umeå/Sweden

Study/Objective: To study perceived collaboration among mining workers and managers, rescue service personnel, and ambulance personnel when mining incidents occur.

Background: Studies focused on rescue operations in mining incidents and on the emergency medical service's part in the rescue operations are scarce. In Sweden, usually the local rescue and ambulance services are dispatched to mining incidents. In a Swedish study, it was found that about one-half of the ambulance personnel in mining districts felt unprepared for managing mining incidents, and almost all the personnel desired to learn more about mining incidents.

Methods: Six focus group discussions were performed that included mining workers and managers, rescue service personnel, and ambulance personnel that have a mine in their uptake area in the county of Västerbotten, Sweden. Additionally, ten complementary individual interviews with ambulance personnel were undertaken. The interviews were transcribed verbatim and analyzed with qualitative content analysis.

Results: The rescue service personnel and the mining personnel perceived their collaboration to be good, but there are still things to consider, eg, being sure that all rescue personnel are willing to enter the mine. During a fire in the Kristineberg mine 2013, several difficulties arose uncovering the need for further collaboration. The ambulance personnel were mostly left out of the collaboration, as most often they waited for the injured to be brought up from the mine. Both the rescue service personnel and ambulance personnel need to rely on the mining personnel when entering the mine, which can lead to difficulties.

Conclusion: There is a need to prepare for major injury incidents in a mine, eg, a fire incident with several injured. Therefore, the three organizations need to collaborate more closely, especially the ambulance personnel need to be included more.

Prehosp Disaster Med 2017;32(Suppl. 1):s173

doi:10.1017/S1049023X17004630

\section{Early Implementation of BLS, Determining the Effectiveness of Cardiopulmonary Resuscitation Stawomir Pilip ${ }^{1}$, Daniel Celinski $i^{1}$, Lukasz Bondaruk ${ }^{1}$, Grzegorz Michalak ${ }^{2}$ \\ 1. Medical University of Warsaw, Warsaw/Poland \\ 2. Medical University of Warsaw, Warsaw/Poland}

Study/Objective: Correlation between the effectiveness of emergency medical actions taken by ambulance medical staff and early BLS implementation in cases of a sudden cardiac arrest was investigated. 